\title{
Radiotracer Technique in Study of Strongly Basic Anion Exchange Resins Dowex-SBR LC and Indion-454
}

\author{
P. U. Singare \\ Department of Chemistry, Bhavan's College, Munshi Nagar, Andheri (West), Mumbai 400 058, India \\ Tel No. + 9122 26256451/ 52 (Office); Fax No. + 912226256453 (Office) \\ *E-mail address: pravinsingare@gmail.com
}

\begin{abstract}
The present paper demonstrates application of isotopic tracer technique in characterization of anion exchange resins Dowex-SBR LC and Indion-454 for which ${ }^{131} \mathrm{I}$ and ${ }^{82} \mathrm{Br}$ radio isotopes were used. The characterization was made based on iodide and bromide ion-isotopic exchange reaction kinetic data obtained for the two resins. It was observed that during iodide ion-isotopic exchange reaction performed at $35.0^{\circ} \mathrm{C}, 1.000 \mathrm{~g}$ of ion exchange resins and $0.002 \mathrm{~mol} / \mathrm{L}$ labeled iodide ion solution, the values of specific reaction rate $\left(\mathrm{min}^{-1}\right)$, amount of ion exchanged (mmol), initial rate of ion exchange $(\mathrm{mmol} / \mathrm{min})$ and $\log \mathrm{K}_{\mathrm{d}}$ were $0.379,0.426,0.161$ and 16.2 respectively for Dowex-SBR LC resin, which was higher than the respective values of $0.156,0.243,0.038$ and 13.4 as that obtained by using Indion-454 resins. The identical trend was observed for the two resins during bromide ionisotopic exchange reaction. The results of present investigation also indicate that during the two ionisotopic exchange reactions, for both the resins, there exists a strong positive linear correlation between amount of ions exchanged and concentration of ionic solution; and strong negative correlation between amount of ions exchanged and temperature of exchanging medium. Based on overall results it appears that under identical experimental conditions, as compared to Indion-454 resins, Dowex-SBR LC resins show superior performance. It is expected here that the present technique can be extended further for characterization of different ion exchange resins which will further help in the selection of those reins for the specific industrial application.
\end{abstract}

Keywords: anion exchange resins; Indion-454; Dowex-SBR LC; radio isotopes; ${ }^{131} \mathrm{I}$; ${ }^{82} \mathrm{Br}$; ion-isotopic exchange reaction; reaction kinetics; characterization

\section{INTRODUCTION}

Industrial applications of radioisotopes can be mainly categorized into two. The first one being the use of radiation from sealed sources of radioisotopes or from electron beam accelerators for industrial processing, non-destructive testing. The second major group of applications is the use of radiotracers in inventory control, study of process parameters, trouble shooting in industrial systems, flow measurements, leakage studies etc. Industrial applications of radioisotopes ensure good quality products and bring down the cost of manufacture by ways of sensitive non-destructive testing and efficient in-process control. Radiotracers have helped in identification of leaks in buried pipelines and dams. Process parameters such as mixing efficiency, residence time, flow rate, material inventory and silt 
movement in harbours are studied using radioisotopes [1]. The efficiency of several devices in a wastewater treatment plant (primary and secondary clarifiers, aeration tank) is investigated by means of radiotracers [2]. Radioisotopes are also employed in certain manufacturing processes to induce desired chemical reactions [1]. Thus radioisotopes have become useful tool and almost every branch of industry uses them [1]. Radioisotope tracers offer several advantages such as high detection sensitivity, capability of in-situ detection, limited memory effects and physic-chemical compatibility with the material under study. Unlike many other advanced technologies, isotope applications have a very low gestation period. A technology developed in the laboratory is often successfully applied in the field within a very short time span. Generally the radioisotopes in suitable physical and chemical forms are introduced in systems under study. By monitoring the radioactivity both continuously or after sampling (depending on the nature of study), the movement, adsorption, retention etc. of the tracer and in turn, of the bulk matter under investigation, can be followed. This make isotope technology one of the highly visible peaceful uses of nuclear energy and a major reason for continuing with nuclear research. Radiotracer methodology is described extensively in the literature [29]. Considering the extensive technological application of radioactive tracers, in the present investigation, attempts are made to assess the performance of Dowex-SBR LC (nuclear grade) and Indion-454 (non-nuclear grade) ion exchange resins under different experimental conditions by application of tracer technique.

\section{EXPERIMENTAL}

\section{1. Conditioning of ion exchange resins}

Dowex-SBR LC is a strongly basic, quaternary ammonium Type I nuclear grade anion exchange resins in hydroxide form (by Dow Chemical Company, Midland, Michigan) while Indion-454 is a strongly basic anion exchange resin in chloride form (by Ion Exchange India Ltd., Mumbai). Details regarding the properties of the resins used are given in Table 1 . These resins were converted separately in to iodide / bromide form by treatment with $10 \% \mathrm{KI} / \mathrm{KBr}$ solution in a conditioning column which is adjusted at the flow rate as $1 \mathrm{~mL} / \mathrm{min}$. The resins were then washed with double distilled water, until the washings were free from iodide/bromide ions as tested by $\mathrm{AgNO}_{3}$ solution. These resins in bromide and iodide form were then dried separately over $\mathrm{P}_{2} \mathrm{O}_{5}$ in desiccators at room temperature.

Table 1. Properties of ion exchange resins.

\begin{tabular}{|c|c|c|c|c|c|c|c|}
\hline $\begin{array}{c}\text { Ion } \\
\text { exchange } \\
\text { resin }\end{array}$ & Matrix & $\begin{array}{c}\text { Functional } \\
\text { Group }\end{array}$ & $\begin{array}{c}\text { Particle } \\
\text { Size } \\
(\mathrm{mm})\end{array}$ & $\begin{array}{c}\text { Moisture } \\
\text { content } \\
(\%)\end{array}$ & $\begin{array}{c}\text { Operating } \\
\mathrm{pH}\end{array}$ & $\begin{array}{c}\text { Maximum } \\
\text { operating } \\
\text { temperatur } \\
\mathrm{e} \\
\left({ }^{\circ} \mathrm{C}\right)\end{array}$ & $\begin{array}{c}\text { Total } \\
\text { exchange } \\
\text { capacity } \\
(\mathrm{mEq} . / \mathrm{mL})\end{array}$ \\
\hline $\begin{array}{c}\text { Dowex- } \\
\text { SBR LC }\end{array}$ & $\begin{array}{c}\text { Styrene- } \\
\text { DVB, Gel }\end{array}$ & $-\mathrm{N}+\mathrm{R} 3$ & $\begin{array}{c}0.30- \\
1.20\end{array}$ & 60 & $0-14$ & 60 & 1.2 \\
\hline $\begin{array}{c}\text { Indion- } \\
454\end{array}$ & $\begin{array}{c}\text { Styrene- } \\
\text { DVB }\end{array}$ & $-\mathrm{N}+\mathrm{R} 3$ & $\begin{array}{c}0.75- \\
0.15\end{array}$ & $\leq 10$ & $0-14$ & 60 & 3.80 \\
\hline
\end{tabular}




\section{2. Radioactive Tracer Isotopes}

The radioisotope ${ }^{131} \mathrm{I}$ and ${ }^{82} \mathrm{Br}$ used in the present experimental work was obtained from Board of Radiation and Isotope Technology (BRIT), Mumbai, India. Details regarding the isotopes used in the present experimental work are given in Table 2.

Table 2. Properties of ${ }^{131} \mathrm{I}$ and ${ }^{82} \mathrm{Br}$ tracer isotopes [1].

\begin{tabular}{|c|c|c|c|c|c|}
\hline Isotopes & Half-life & $\begin{array}{c}\text { Radioactivity } \\
/ \mathrm{mCi}\end{array}$ & $\begin{array}{c}\boldsymbol{\gamma} \text { - energy } \\
/ \mathrm{MeV}\end{array}$ & $\begin{array}{c}\text { Chemical } \\
\text { form }\end{array}$ & $\begin{array}{c}\text { Physical } \\
\text { form }\end{array}$ \\
\hline${ }^{131} \mathrm{I}$ & $8.04 \mathrm{~d}$ & 5 & 0.36 & Iodide* & Aqueous \\
\hline${ }^{82} \mathrm{Br}$ & $36 \mathrm{~h}$ & 5 & 0.55 & Bromide** & Aqueous \\
\hline
\end{tabular}

* Sodium iodide in dilute sodium sulphite.

** Ammonium bromide in dilute ammonium hydroxide.

\section{3. Study on kinetics of iodide ion-isotopic exchange reaction}

In a stoppered bottle $250 \mathrm{~mL}(V)$ of $0.001 \mathrm{~mol} / \mathrm{L}$ iodide ion solution was labeled with diluted ${ }^{131}$ I radioactive solution using a micro syringe, such that $1.0 \mathrm{~mL}$ of labeled solution has a radioactivity of around $15,000 \mathrm{cpm}$ (counts per minute) when measured with $\gamma$-ray spectrometer having $\mathrm{NaI}(\mathrm{Tl})$ scintillation detector.

Since only about $50-100 \mu \mathrm{L}$ of the radioactive iodide ion solution was required for labeling the solution, its concentration will remain unchanged, which was further confirmed by potentiometer titration against $\mathrm{AgNO}_{3}$ solution.

The above labeled solution of known initial activity $\left(A_{i}\right)$ was kept in a thermostat adjusted to $30.0{ }^{\circ} \mathrm{C}$. The swelled and conditioned dry ion exchange resins in iodide form weighing exactly $1.000 \mathrm{~g}(\mathrm{~m})$ were transferred quickly into this labeled solution which was vigorously stirred by using mechanical stirrer and the activity in cpm of $1.0 \mathrm{~mL}$ of solution was measured.

The solution was transferred back to the same bottle containing labeled solution after measuring activity. The iodide ion-isotopic exchange reaction can be represented as:

$$
\mathrm{R}-\mathrm{I}+\mathrm{I}^{*-}{ }_{(\text {aq. })} \rightleftharpoons \mathrm{R}-\mathrm{I}^{*}+\mathrm{I}^{-}{ }_{\text {(aq.) }}
$$

here R-I represents ion exchange resin in iodide form; $\mathrm{I}^{*^{-}}{ }_{(\text {aq. }}$ represents aqueous iodide ion solution labeled with ${ }^{131}$ I radiotracer isotope. The activity of solution was measured at a fixed interval of every $2.0 \mathrm{~min}$ [19-21].

The final activity $\left(A_{f}\right)$ of the solution was also measured after $3 \mathrm{~h}$ which was sufficient time to attain the equilibrium [10-14].

The activity measured at various time intervals was corrected for background counts. Similar experiments were carried out by equilibrating separately $1.000 \mathrm{~g}$ of ion exchange resin in iodide form with labeled iodide ion solution of four different concentrations ranging up to $0.004 \mathrm{~mol} / \mathrm{L}$ at a constant temperature of $30.0^{\circ} \mathrm{C}$.

The same experimental sets were repeated for higher temperatures up to $45.0^{\circ} \mathrm{C}$. 


\section{4. Study on kinetics of bromide ion-isotopic exchange reaction}

The experiment was also performed to study the kinetics of bromide ion- isotopic exchange reaction by equilibrating $1.000 \mathrm{~g}$ of ion exchange resin in bromide form with labeled bromide ion solution in the same concentration and temperature range as above. The labeling of bromide ion solution was done by using ${ }^{82} \mathrm{Br}$ as a radioactive tracer isotope for which the same procedure as explained above was followed. The bromide ion-isotopic exchange reaction can be represented as:

$$
\mathrm{R}-\mathrm{Br}+\mathrm{Br}^{*-}{ }_{(\text {aq. })} \rightleftharpoons \mathrm{R}-\mathrm{Br}^{*}+\mathrm{Br}^{-}{ }_{(\text {aq. })}
$$

here $\mathrm{R}-\mathrm{Br}$ represents ion exchange resin in bromide form; $\mathrm{Br}^{*-}{ }_{\text {(aq.) }}$ represents aqueous bromide ion solution labeled with ${ }^{82} \mathrm{Br}$ radiotracer isotope [19-21].

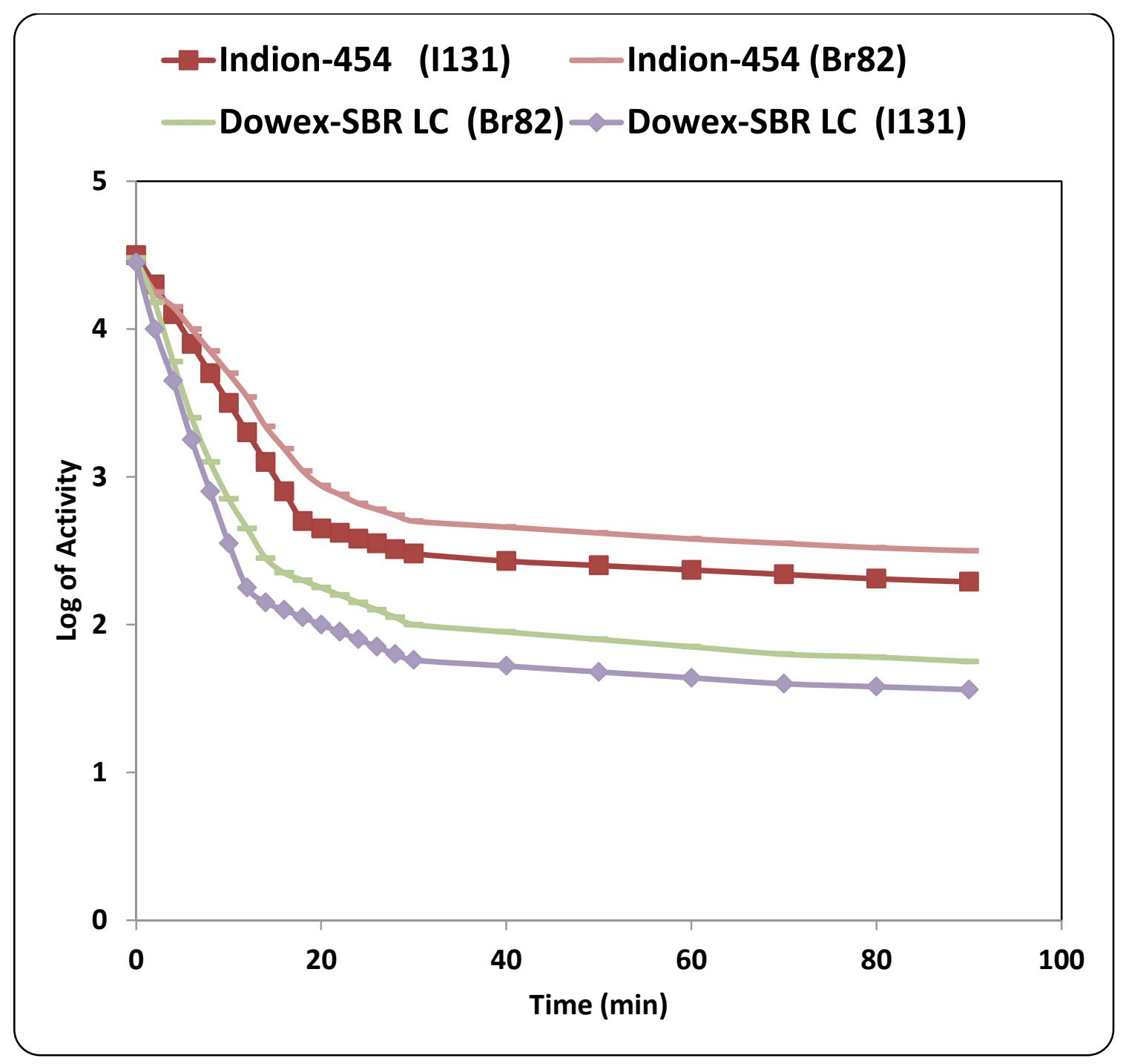

Figure 1. Kinetics of Ion-Isotopic Exchange Reactions.

Amount of ion exchange resin $=1.000 \mathrm{~g}$, Concentration of labeled exchangeable ionic solution $=0.002 \mathrm{~mol} / \mathrm{L}$, Volume of labeled ionic solution $=250 \mathrm{~mL}$, Temperature $=35.0^{\circ} \mathrm{C}$ 


\begin{tabular}{|c|c|c|c|c|c|c|}
\hline$\stackrel{\circ}{\circ}$ & : & i̊ & $\stackrel{0}{8}$ & \multicolumn{3}{|c|}{$\begin{array}{l}\text { Concentration of ionic solution } \\
(\mathrm{mol} / \mathrm{L})\end{array}$} \\
\hline$\dot{\dot{8}}$ & $\stackrel{0}{\dot{v}}$ & ì & $\stackrel{0}{\text { in }}$ & \multicolumn{3}{|c|}{$\begin{array}{l}\text { Amount of ions in } 250 \mathrm{~mL} \text { solution } \\
\qquad(\mathrm{mmol})\end{array}$} \\
\hline $\begin{array}{l}0 \\
\dot{1} \\
\dot{0}\end{array}$ & i & $i_{0}^{0}$ & i & $\begin{array}{l}\text { Specific reaction rate of } \\
\text { rapid process } \\
\min ^{-1}\end{array}$ & \multirow{4}{*}{ 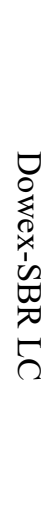 } & \multirow{8}{*}{ 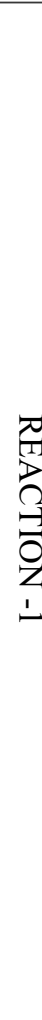 } \\
\hline $\begin{array}{l}\infty \\
\infty \\
\infty \\
+\infty\end{array}$ & $\begin{array}{l}\dot{0} \\
\dot{u}\end{array}$ & $\begin{array}{l}\ddot{D}_{n} \\
\text { Na }\end{array}$ & i & $\begin{array}{l}\text { Amount of iodide ion } \\
\text { exchanged (mmol) }\end{array}$ & & \\
\hline 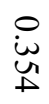 & $\begin{array}{l}0 \\
\text { in } \\
\text { W }\end{array}$ & $\stackrel{\circ}{\circ}$ & $\begin{array}{l}\stackrel{0}{0} \\
\stackrel{9}{y}\end{array}$ & $\begin{array}{l}\text { Initial rate of iodide ion } \\
\text { exchange }(\mathrm{mmol} / \mathrm{min})\end{array}$ & & \\
\hline$\underset{\perp}{\infty}$ & $\underset{i}{\vec{v}}$ & $\vec{i}$ & $\vec{i}$ & $\log \mathrm{K}_{\mathrm{d}}$ & & \\
\hline$\stackrel{0}{i}$ & $\stackrel{\circ}{\circ}$ & $\stackrel{0}{\text { ŭ }^{\prime}}$ & $\stackrel{0}{\stackrel{0}{+}}$ & $\begin{array}{l}\text { Specific reaction rate of } \\
\text { rapid process } \\
\min ^{-1}\end{array}$ & \multirow{4}{*}{ 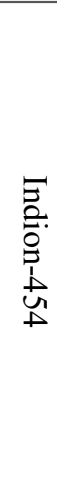 } & \\
\hline in & $\underset{\infty}{\infty}$ & $\stackrel{0}{i}$ & $\stackrel{0}{\check{E}}$ & $\begin{array}{l}\text { Amount of iodide ion } \\
\text { exchanged } \\
(\mathrm{mmol})\end{array}$ & & \\
\hline $\begin{array}{l}\stackrel{0}{\circ} \\
\stackrel{\circ}{\circ}\end{array}$ & $\begin{array}{l}\stackrel{0}{\circ} \\
\stackrel{\circ}{+}\end{array}$ & 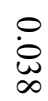 & $\begin{array}{l}\stackrel{0}{0} \\
\stackrel{0}{V}\end{array}$ & $\begin{array}{l}\text { Initial rate of iodide ion } \\
\text { exchanged (mmol/min) }\end{array}$ & & \\
\hline $\begin{array}{l}\vec{n} \\
\dot{a}\end{array}$ & $\overrightarrow{\vec{A}}$ & $\underset{\phi}{\omega}$ & $\vec{w}$ & $\log K_{d}$ & & \\
\hline$\stackrel{i}{u}_{\dot{w}}$ & $\begin{array}{l}0 \\
\dot{\omega} \\
+\end{array}$ & $\stackrel{0}{\omega}_{N}^{\omega}$ & $\begin{array}{l}0 \\
i \\
\tilde{o}\end{array}$ & $\begin{array}{l}\text { Specific reaction rate of } \\
\text { rapid process } \\
\text { min }^{-1}\end{array}$ & \multirow{4}{*}{ 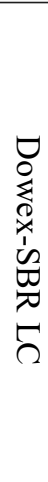 } & \multirow{8}{*}{ 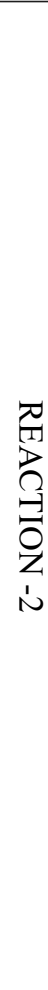 } \\
\hline$\stackrel{\circ}{\infty}$ & î & $\underset{\infty}{\infty}$ & $\stackrel{0}{i}$ & $\begin{array}{c}\text { Amount of bromide ion } \\
\text { exchanged } \\
(\mathrm{mmol})\end{array}$ & & \\
\hline$\underset{\infty}{\infty}$ & $\begin{array}{l}0 \\
\text { ĩ } \\
\text { cin }\end{array}$ & $\stackrel{0}{i}$ & $\stackrel{\circ}{\circ}$ & $\begin{array}{l}\text { Initial rate of bromide ion } \\
\text { exchange }(\mathrm{mmol} / \mathrm{min})\end{array}$ & & \\
\hline Е & $\stackrel{0}{0}$ & $\underset{i}{\vec{i}}$ & $\begin{array}{l}0 \\
0\end{array}$ & $\log K_{d}$ & & \\
\hline$\stackrel{0}{\dot{n}}$ & $\stackrel{0}{i}$ & $\stackrel{0}{\stackrel{\sim}{\perp}}$ & $\stackrel{0}{\dot{N}_{n}}$ & $\begin{array}{l}\text { Specific reaction rate of } \\
\text { rapid process } \\
\min ^{-1}\end{array}$ & \multirow{4}{*}{ 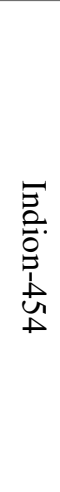 } & \\
\hline $\begin{array}{l}0 \\
\dot{\infty} \\
\infty \\
\infty\end{array}$ & $\underset{i}{\stackrel{0}{+}}$ & $\stackrel{0}{\stackrel{0}{\omega}}$ & $\stackrel{\circ}{\circ}$ & $\begin{array}{c}\text { Amount of bromide ion } \\
\text { exchanged } \\
(\mathrm{mmol})\end{array}$ & & \\
\hline $\begin{array}{l}\stackrel{0}{0} \\
\stackrel{\circ}{\alpha}\end{array}$ & $\begin{array}{l}0 \\
\dot{0} \\
\dot{0}\end{array}$ & $\begin{array}{l}\stackrel{0}{\dot{O}} \\
\text { No }\end{array}$ & $\begin{array}{l}\stackrel{\circ}{0} \\
\stackrel{0}{N}\end{array}$ & $\begin{array}{l}\text { Initial rate of bromide ion } \\
\text { exchange }(\mathrm{mmol} / \mathrm{min})\end{array}$ & & \\
\hline lo & $\stackrel{\infty}{i}$ & $\infty$ & is & $\log \mathrm{K}_{\mathrm{d}}$ & & \\
\hline
\end{tabular}




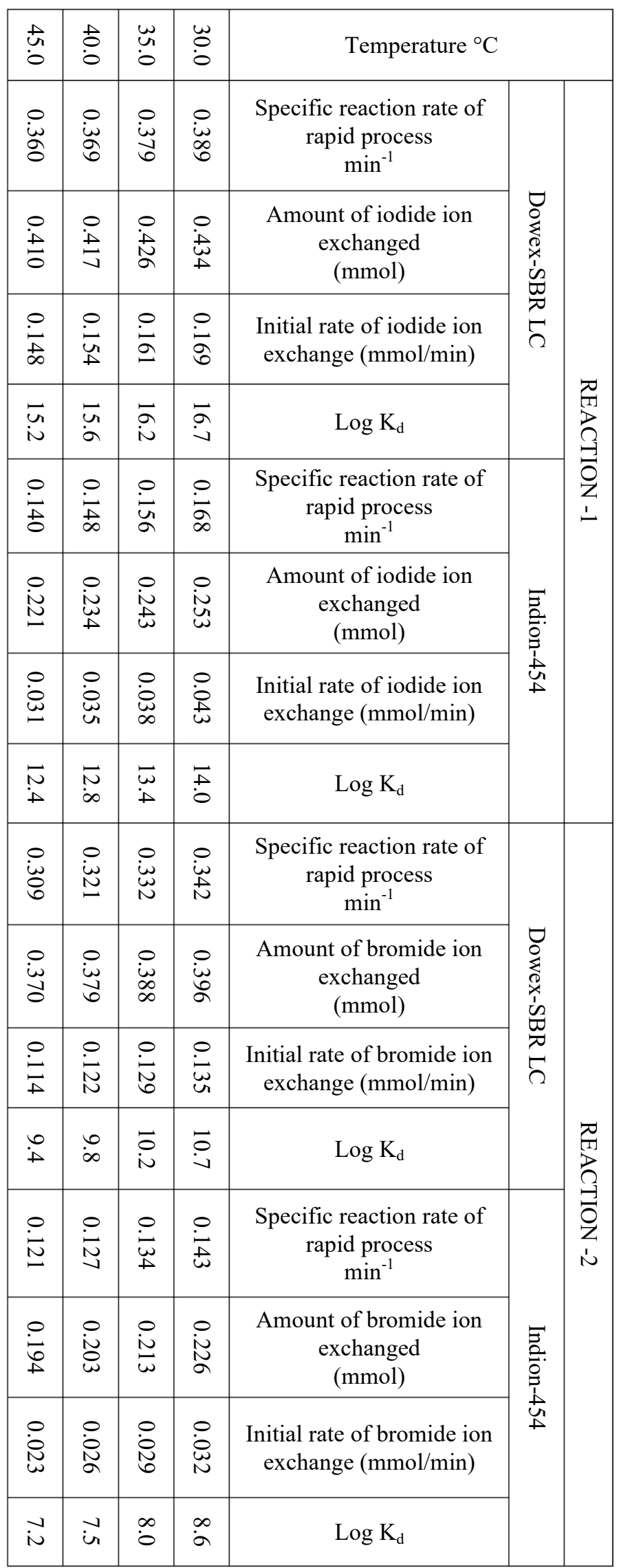

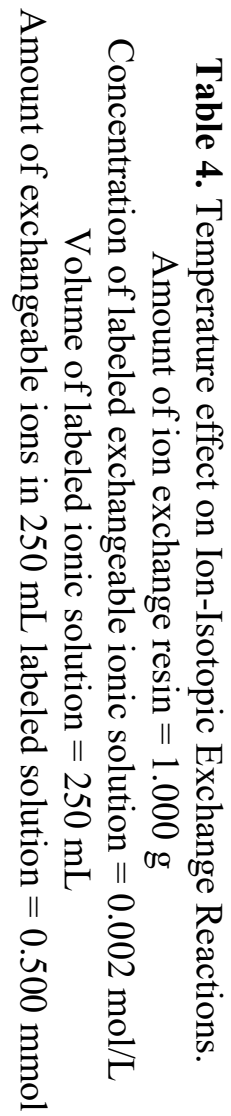




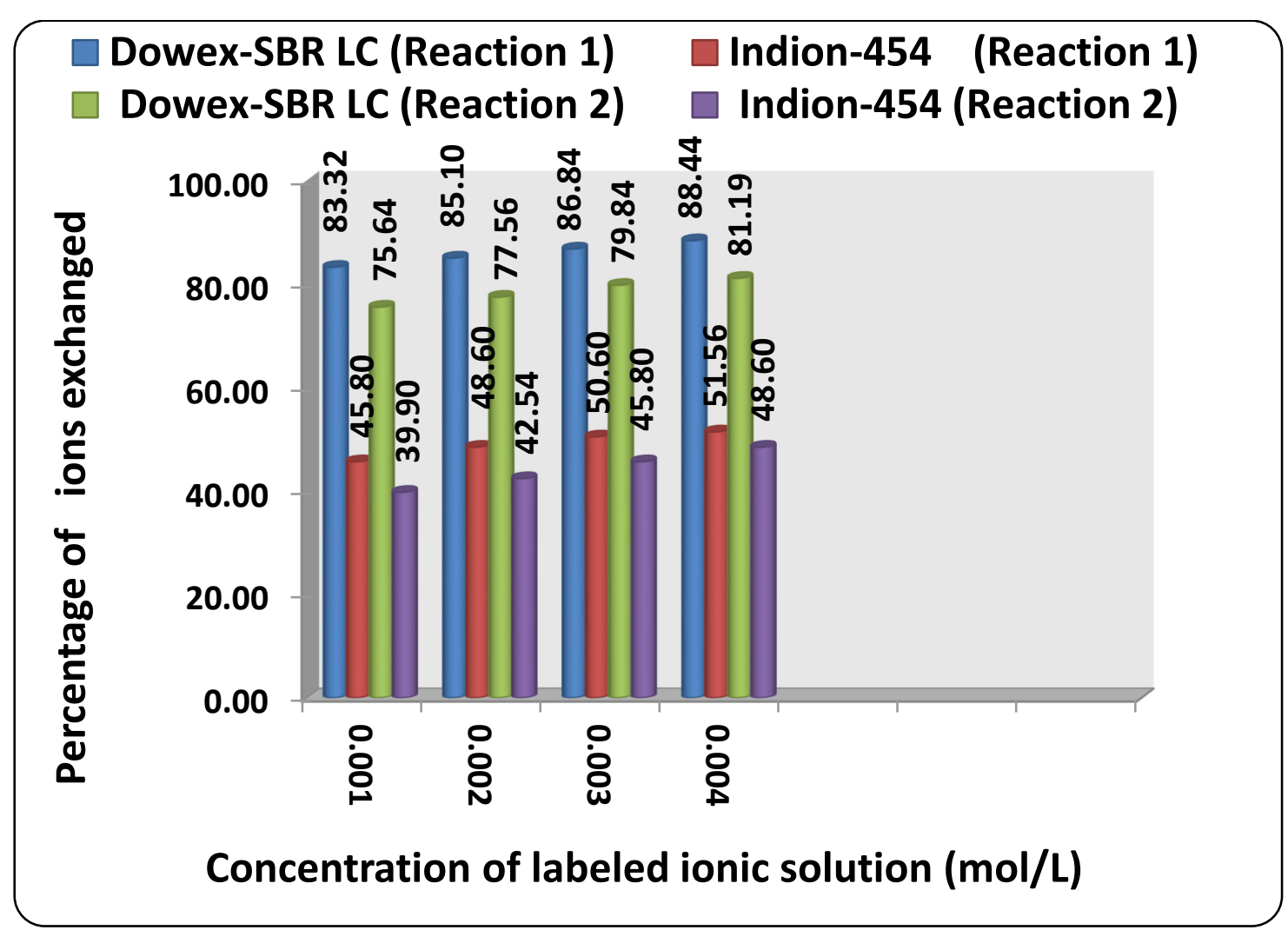

Figure 2. Variation in Percentage Ions Exchanged with Concentration of Labeled Ionic Solution. Amount of ion exchange resin $=1.000 \mathrm{~g}$, Volume of labeled ionic solution $=250 \mathrm{~mL}$, Temperature $=35.0{ }^{\circ} \mathrm{C}$

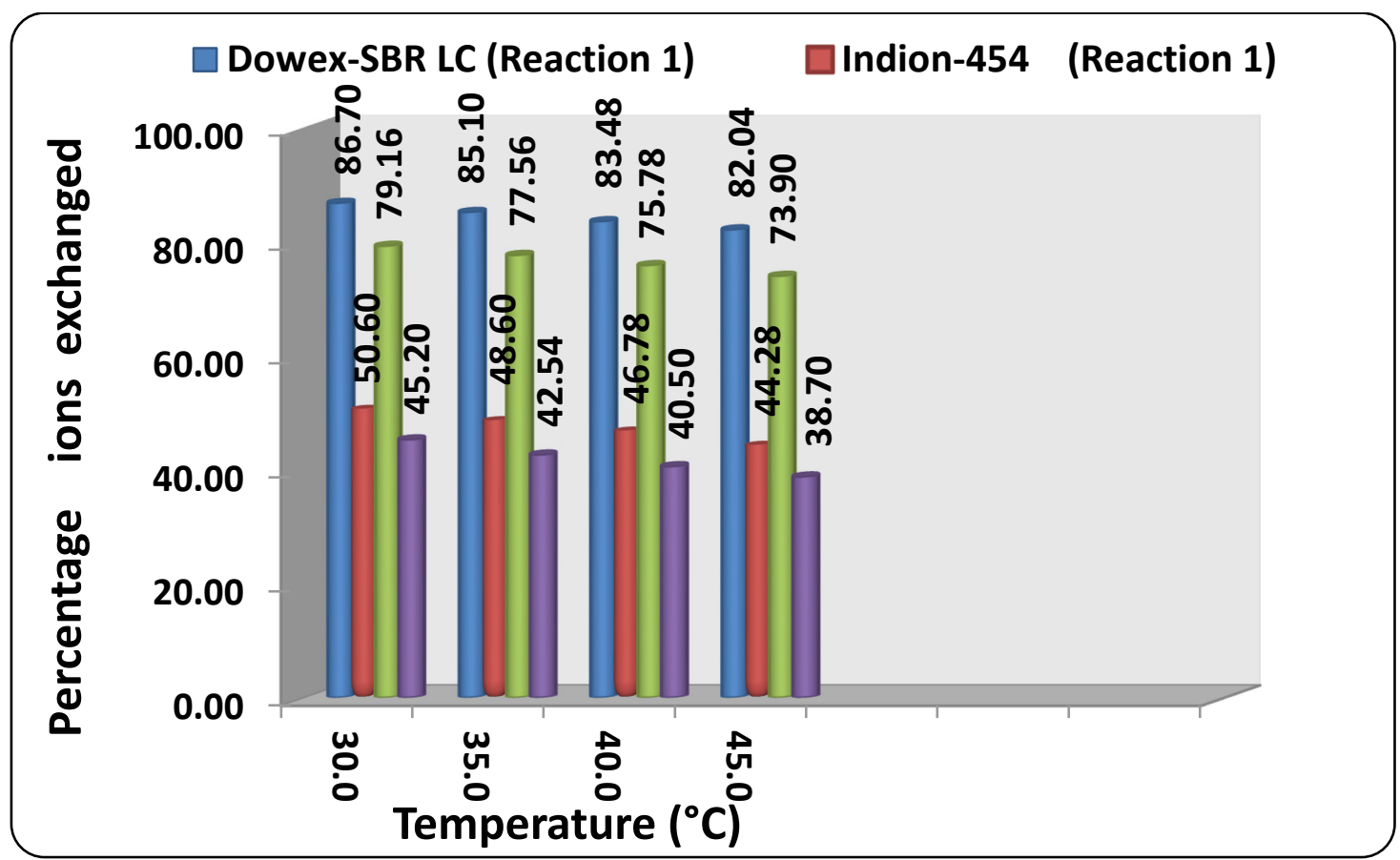

Figure 3. Variation in Percentage Ions Exchanged with Temperature of Labeled Ionic Solution. Amount of ion exchange resin $=1.000 \mathrm{~g}$, Concentration of labeled exchangeable ionic solution $=0.002 \mathrm{~mol} / \mathrm{L}$, Volume of labeled ionic solution $=250 \mathrm{~mL}$, Amount of exchangeable ions in $250 \mathrm{~mL}$ labeled solution $=0.500 \mathrm{mmol}$ 


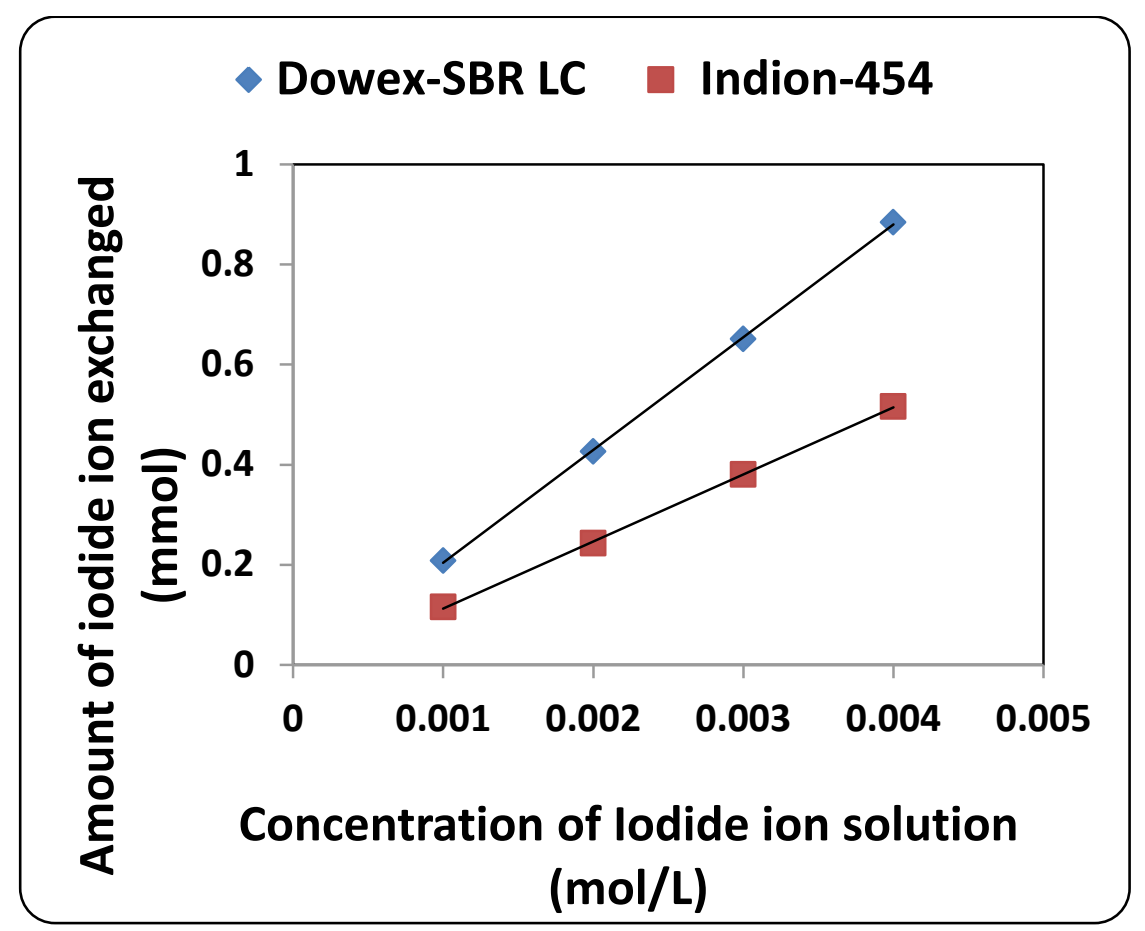

Figure 4. Correlation between concentration of iodide ion solution and amount of iodide ion exchanged.

Amount of ion exchange resin $=1.000 \mathrm{~g}$, Volume of labeled ionic solution $=250 \mathrm{~mL}$, Temperature $=35.0{ }^{\circ} \mathrm{C}$ Correlation coefficient ( $\mathrm{r}$ ) for Dowex-SBR LC $=0.9999$

Correlation coefficient (r) for Indion-454 $=0.9999$

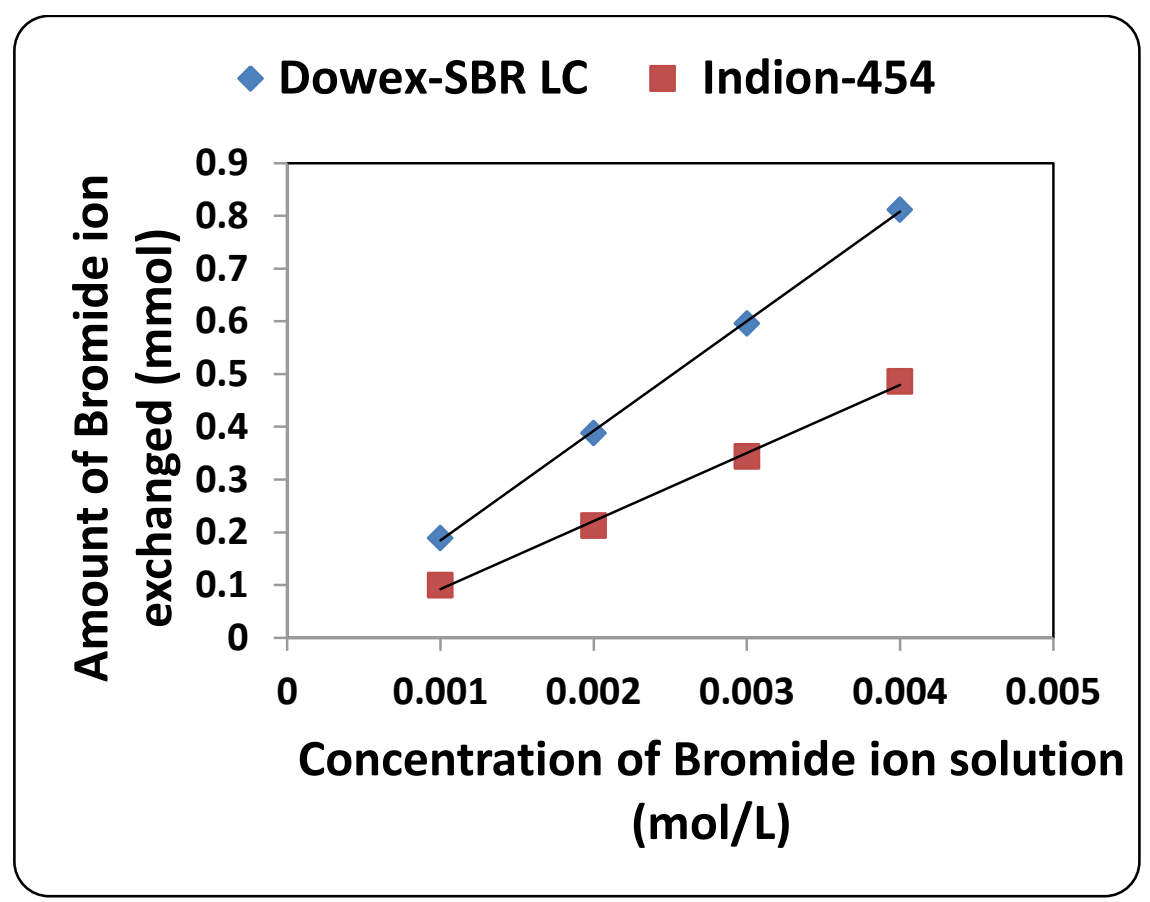

Figure 5. Correlation between concentration of bromide ion solution and amount of bromide ion exchanged.

Amount of ion exchange resin $=1.000 \mathrm{~g}$, Volume of labeled ionic solution $=250 \mathrm{~mL}$, Temperature $=35.0^{\circ} \mathrm{C}$ Correlation coefficient ( $\mathrm{r}$ ) for Dowex-SBR LC $=0.9998$

Correlation coefficient (r) for Indion-454 $=0.9987$ 


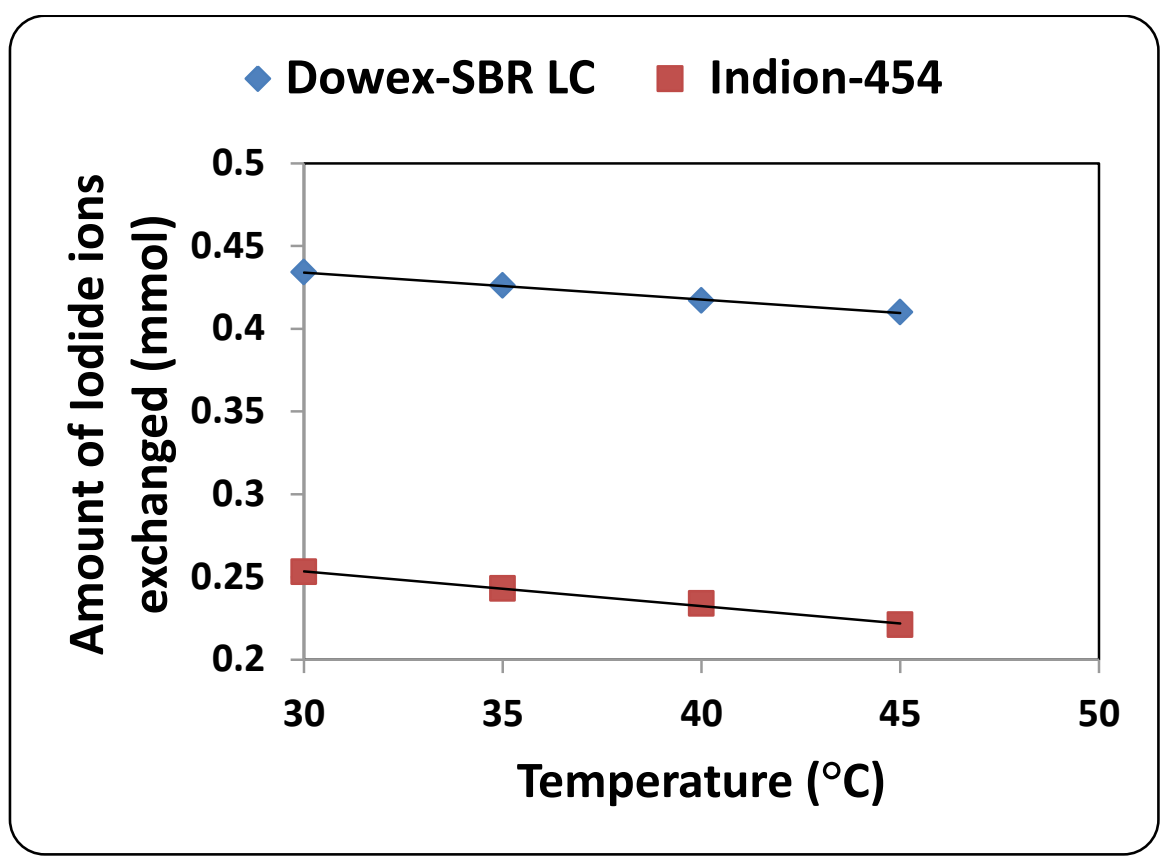

Figure 6: Correlation between Temperature of exchanging medium and amount of iodide ion exchanged.

Amount of ion exchange resin $=1.000 \mathrm{~g}$, Concentration of labeled exchangeable ionic solution $=0.002 \mathrm{~mol} / \mathrm{L}$, Volume of labeled ionic solution $=250 \mathrm{~mL}$, Amount of exchangeable ions in $250 \mathrm{~mL}$ labeled solution $=0.500$ mmol, Correlation coefficient ( $\mathrm{r}$ ) for Dowex-SBR LC $=-0.9989$

Correlation coefficient $(r)$ for Indion-454 $=-0.9968$

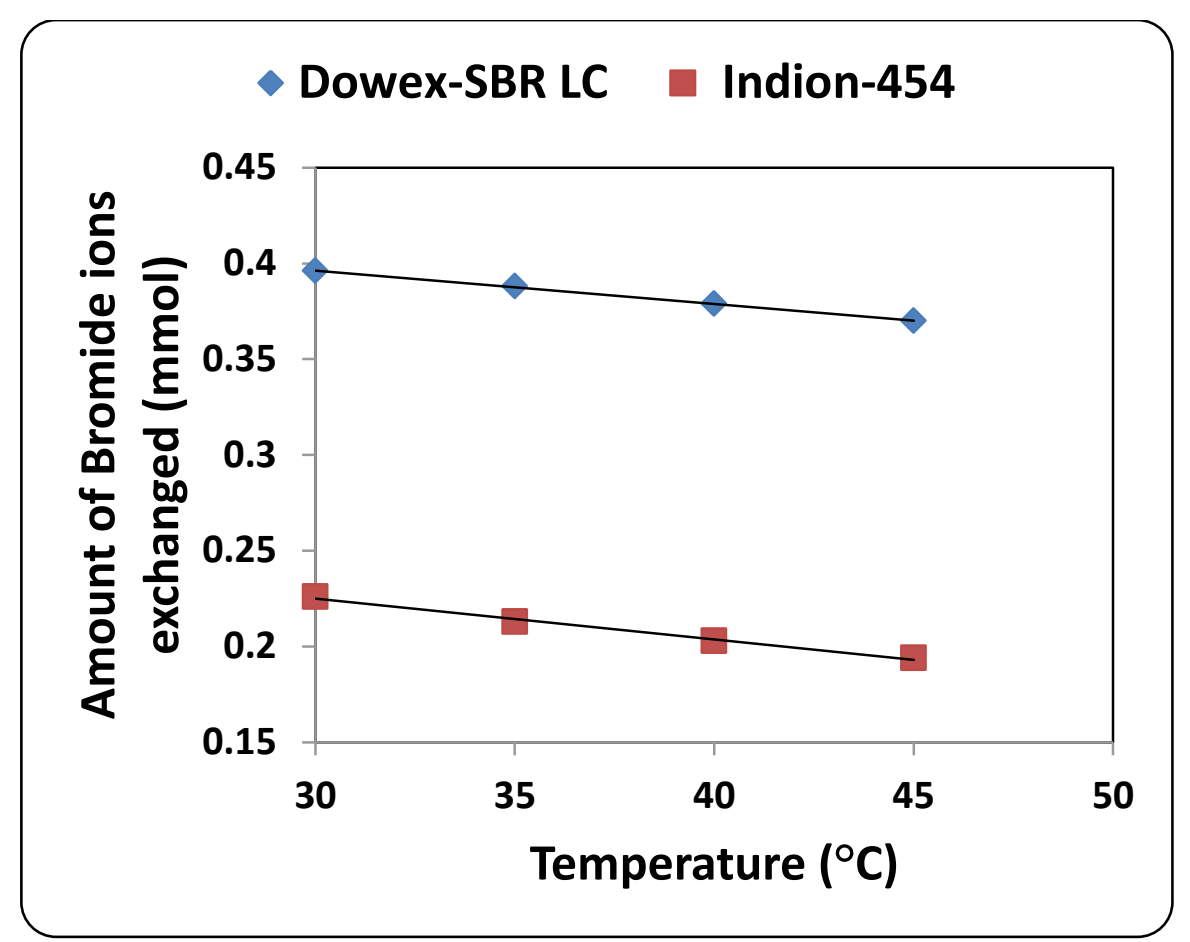

Figure 7. Correlation between Temperature of exchanging medium and amount of bromide ion exchanged.

Amount of ion exchange resin $=1.000 \mathrm{~g}$, Concentration of labeled exchangeable ionic solution $=0.002 \mathrm{~mol} / \mathrm{L}$, Volume of labeled ionic solution $=250 \mathrm{~mL}$, Amount of exchangeable ions in $250 \mathrm{~mL}$ labeled solution $=0.500$ mmol, Correlation coefficient (r) for Dowex-SBR LC $=-0.9996$,

Correlation coefficient $(r)$ for Indion-454 $=-0.9963$ 


\section{RESULTS AND DISCUSSION}

\section{1. Comparative study of ion-isotopic exchange reactions}

In the present investigation it was observed that due to the rapid ion-isotopic exchange reaction taking place, the activity of solution decreases rapidly initially, then due to the slow exchange the activity of the solution decreases slowly and finally remains nearly constant. Preliminary studies show that the above exchange reactions are of first order [10-14]. Therefore logarithm of activity when plotted against time gives a composite curve in which the activity initially decreases sharply and thereafter very slowly giving nearly straight line (Figure 1), evidently rapid and slow ion-isotopic exchange reactions were occurring simultaneously [10-14]. Now the straight line was extrapolated back to zero time. The extrapolated portion represents the contribution of slow process to the total activity which now includes rapid process also. The activity due to slow process was subtracted from the total activity at various time intervals. The difference gives the activity due to rapid process only. From the activity exchanged due to rapid process at various time intervals, the specific reaction rates $(k)$ of rapid ion-isotopic exchange reaction were calculated. The amount of iodide / bromide ions exchanged ( $\mathrm{mmol}$ ) on the resin were obtained from the initial and final activity of solution and the amount of exchangeable ions in $250 \mathrm{~mL}$ of solution. From the amount of ions exchanged on the resin $(\mathrm{mmol})$ and the specific reaction rates $\left(\mathrm{min}^{-1}\right)$, the initial rate of ion exchanged $(\mathrm{mmol} / \mathrm{min})$ was calculated.

Because of larger solvated size of bromide ions as compared to that of iodide ions, it was observed that the exchange of bromide ions occurs at the slower rate than that of iodide ions. Hence under identical experimental conditions, the values of specific reaction rate $\left(\mathrm{min}^{-}\right.$ $\left.{ }^{1}\right)$, amount of ion exchanged ( $\left.\mathrm{mmol}\right)$ and initial rate of ion exchange $(\mathrm{mmol} / \mathrm{min})$ are calculated to be lower for bromide ion-isotopic exchange reaction than that for iodide ionisotopic exchange reaction as summarized in Tables 3 and 4. For both bromide and iodide ion-isotopic exchange reactions, under identical experimental conditions, the values of specific reaction rate increases with increase in the concentration of iodide and bromide ions in solution from $0.001 \mathrm{~mol} / \mathrm{L}$ to $0.004 \mathrm{~mol} / \mathrm{L}$ (Table 3). However, with rise in temperature from $30.0{ }^{\circ} \mathrm{C}$ to $45.0{ }^{\circ} \mathrm{C}$, the specific reaction rate was observed to decrease (Table 4). Thus in case of Dowex-SBR LC at $35.0^{\circ} \mathrm{C}$ when the concentration of iodide and bromide ions in solution increases from $0.001 \mathrm{~mol} / \mathrm{L}$ to $0.004 \mathrm{~mol} / \mathrm{L}$, the specific reaction rate values for iodide ion-isotopic exchange increases from 0.368 to $0.400 \mathrm{~min}^{-1}$, while for bromide ionisotopic exchange the values increases from 0.320 to $0.355 \mathrm{~min}^{-1}$. Similarly in case of Indion454 , under identical experimental conditions, the values for iodide ion-isotopic exchange increases from 0.145 to $0.182 \mathrm{~min}^{-1}$, while for bromide ion-isotopic exchange the values increases from 0.125 to $0.156 \mathrm{~min}^{-1}$. However when the concentration of iodide and bromide ions in solution is kept constant at $0.002 \mathrm{~mol} / \mathrm{L}$ and temperature is raised from $30.0{ }^{\circ} \mathrm{C}$ to 45.0 ${ }^{\circ} \mathrm{C}$, in case of Dowex-SBR LC the specific reaction rate values for iodide ion-isotopic exchange decreases from 0.389 to $0.360 \mathrm{~min}^{-1}$, while for bromide ion-isotopic exchange the values decreases from 0.342 to $0.309 \mathrm{~min}^{-1}$. Similarly in case of Indion-454, under identical experimental conditions, the specific reaction rate values for iodide ion-isotopic exchange decreases from 0.168 to $0.140 \mathrm{~min}^{-1}$, while for bromide ion-isotopic exchange the values decreases from 0.143 to $0.121 \mathrm{~min}^{-1}$. From the results, it appears that iodide ions exchange at the faster rate as compared to that of bromide ions which was related to the extent of solvation (Tables 3 and 4).

From the knowledge of $A_{i}, A_{f}$, volume of the exchangeable ionic solution ( $V$ ) and mass of ion exchange resin $(m)$, the $K_{d}$ value was calculated by the equation 


$$
K_{d}=\left[\left(A_{i}-A_{f}\right) / A_{f}\right] \times V / m
$$

Previous studies $[15,16]$ on halide ion distribution coefficient on strong and weak basic anion exchange resins indicate that the selectivity coefficient between halide ions increased at higher electrolyte concentrations. Adachi et al. [17] observed that the swelling pressure of the resin decreased at higher solute concentrations resulting in larger $\mathrm{K}_{\mathrm{d}}$ values. The temperature dependence of $K_{d}$ values on cation exchange resin was studied by Shuji et al. [18]; were they observed that the values of $\mathrm{K}_{\mathrm{d}}$ increased with fall in temperature. The present experimental results also indicates that the $\mathrm{K}_{\mathrm{d}}$ values for bromide and iodide ions increases with increase in ionic concentration of the external solution, however with rise in temperature the $K_{d}$ values were found to decrease. Thus in case of Dowex-SBR LC at $35.0^{\circ} \mathrm{C}$ when the concentration of iodide and bromide ions in solution increases from $0.001 \mathrm{~mol} / \mathrm{L}$ to $0.004 \mathrm{~mol} / \mathrm{L}$, the $\log \mathrm{K}_{\mathrm{d}}$ values for iodide ions increases from 15.1 to 18.4 , while for bromide ions the values increases from 9.6 to 11.2. Similarly in case of Indion-454, under identical experimental conditions, the $\log \mathrm{K}_{\mathrm{d}}$ values for iodide ions increases from 12.3 to 15.6 , while for bromide ions the values increases from 7.4 to 9.0. However when the concentration of iodide and bromide ions in solution is kept constant at $0.002 \mathrm{~mol} / \mathrm{L}$ and temperature is raised from $30.0{ }^{\circ} \mathrm{C}$ to $45.0{ }^{\circ} \mathrm{C}$, in case of Dowex-SBR LC the $\log \mathrm{K}_{\mathrm{d}}$ values for iodide ions decreases from 16.7 to 15.2 , while for bromide ions the values decreases from 10.7 to 9.4. Similarly in case of Indion-454, under identical experimental conditions, the $\log \mathrm{K}_{\mathrm{d}}$ values for iodide ions decreases from 14.0 to 12.4, while for bromide ions the values decreases from 8.6 to 7.2. It was also observed that the $K_{d}$ values for iodide ion-isotopic exchange reaction were calculated to be higher than that for bromide ion-isotopic exchange reaction (Tables 3 and 4).

\section{2. Comparative study of anion exchange resins}

From the Table 3 and 4, it is observed that for iodide ion-isotopic exchange reaction by using Dowex-SBR LC resin, the values of specific reaction rate $\left(\mathrm{min}^{-1}\right)$, amount of iodide ion exchanged (mmol), initial rate of iodide ion exchange $(\mathrm{mmol} / \mathrm{min})$ and $\log \mathrm{K}_{\mathrm{d}}$ were 0.379 , $0.426,0.161$ and 16.2 respectively, which was higher than $0.156,0.243,0.038$ and 13.4 respectively as that obtained by using Indion-454 resins under identical experimental conditions of $35.0^{\circ} \mathrm{C}, 1.000 \mathrm{~g}$ of ion exchange resins and $0.002 \mathrm{~mol} / \mathrm{L}$ labeled iodide ion solution. The identical trend was observed for the two resins during bromide ion-isotopic exchange reaction.

From Table 3, it is observed that at a constant temperature of $35.0{ }^{\circ} \mathrm{C}$, as the concentration of labeled iodide ion solution increases from $0.001 \mathrm{~mol} / \mathrm{L}$ to $0.004 \mathrm{~mol} / \mathrm{L}$, the percentage of iodide ions exchanged increases from $83.32 \%$ to $88.44 \%$ using Dowex-SBR LC resins and from $45.80 \%$ to $51.56 \%$ using Indion-454 resins. Similarly in case of bromide ion-isotopic exchange reactions under identical experimental conditions, the percentage of bromide ions exchanged increases from $75.64 \%$ to $81.19 \%$ using Dowex-SBR LC resin and from $39.90 \%$ to $48.60 \%$ using Indion-454 resin. The effect of ionic concentration on percentage of ions exchanged is graphically represented in Figure 2.

From Table 4, it is observed that for $0.002 \mathrm{~mol} / \mathrm{L}$ labeled iodide ion solution, as the temperature increases from $30.0{ }^{\circ} \mathrm{C}$ to $45.0{ }^{\circ} \mathrm{C}$, the percentage of iodide ions exchanged decreases from $86.70 \%$ to $82.04 \%$ using Dowex-SBR LC resins and from $50.60 \%$ to 44.28 $\%$ using Indion-454 resins. Similarly under identical experimental conditions, in case of bromide ion-isotopic exchange reactions, the percentage of bromide ions exchanged decreases from $79.16 \%$ to $73.90 \%$ using Dowex-SBR LC resin and from $45.20 \%$ to $38.70 \%$ using 
Indion-454 resin. The effect of temperature on percentage of ions exchanged is graphically represented in Figure 3.

The overall results indicate that under identical experimental conditions, as compared to Indion-454 resins, Dowex-SBR LC resins shows higher percentage of ions exchanged. Thus Dowex-SBR LC resins show superior performance over Indion-454 resins under identical operational parameters.

\section{3. Statistical Correlations}

The results of present investigation show a strong positive linear correlation between amount of ions exchanged and concentration of ionic solution (Figures 4, 5). In case of iodide ion-isotopic exchange reaction, the values of correlation coefficient $(r)$ was calculated as 0.9999 for both the resins, while for bromide ion-isotopic exchange reaction, the values of $r$ was calculated as 0.9998 and 0.9987 for Dowex-SBR LC and Indion-454 resins respectively. There also exist a strong negative correlation between amount of ions exchanged and temperature of exchanging medium (Figures 6, 7). In case of iodide ion-isotopic exchange reactions the values of $r$ calculated for Dowex-SBR LC and Indion-454 resins were -0.9989 and -0.9968 respectively. Similarly in case of bromide ion-isotopic exchange reactions the $r$ values calculated were -0.9996 and -0.9963 respectively for the two resins.

\section{CONCLUSION}

The experimental work carried out in the present investigation will help to standardize the operational process parameters so as to improve the performance of selected ion exchange resins. The radioactive tracer technique used here can also be applied further for characterization of different nuclear as well as non-nuclear grade ion exchange resins.

\section{Acknowledgement}

The author is thankful to Professor Dr. R.S. Lokhande (Retired) for his valuable help and support by providing the required facilities so as to carry out the experimental work in Radiochemistry Laboratory, Department of Chemistry, University of Mumbai, Vidyanagari, Mumbai -58.

\section{References}

[1] D. D. Sood, A. V. R. Reddy, N. Ramamoorthy, 'Applications of Radioisotopes In Physico-Chemical Investigations', in Fundamentals of Radiochemistry, Indian Association of Nuclear Chemists and Allied Scientists (IANCAS), pp. 253-263, January 2004.

[2] Radiotracer Applications in Industry - A Guidebook, Technical Reports Series No. 423, IAEA, Vienna 2004.

[3] Clark M. W., Harrison J. J., Payne T. E., Journal of Colloid and Interface Science 356(2) (2011) 699-705.

[4] Dagadu C. P. K., Akaho E. H. K., Danso K. A., Stegowski Z., Furman L., Applied Radiation and Isotopes 70(1) (2012) 156-161. 
[5] Koron N., Bratkic A., Ribeiro Guevara S., Vahcic M., Horvat M., Applied Radiation and Isotopes 70(1) (2012) 46-50.

[6] Meng X., Weiguo L., Analytica Chimica Acta 686 (1) (2011) 107-114.

[7] Randriamanantsoa L., Morel C., Rabeharisoa L., Douzet J. M., Jansa J., Frossard E., Geoderma 200 (2013) 120-129.

[8] Mochizuki K., Munakata K., Wajima T., Hara K., Wada K., Shinozaki T., Takeishi T., Knitter R., Bekris N., Okuno K., Fusion Engineering and Design 85(7) (2010) 1185-1189.

[9] Li Z., Chansaenpak K., Liu S., Wade C. R., Conti P. S., Gabbaï F. P., MedChemComm 3(10) (2012) 1305-1308.

[10] Singare P. U., Lokhande R. S., Ionics 18(4) (2012) 351-357.

[11] Lokhande R. S., Singare P. U., Radiochim. Acta 95(03) (2007) 173-176.

[12] Lokhande R. S., Singare P. U., Patil V. V., Radiochemistry 50(06) (2008) 638-641.

[13] Lokhande R. S., Singare P. U., J. Porous Mater 15(03) (2008) 253-258.

[14] Lokhande R. S., Singare P. U., Dole M. H., J. Nuclear and Radiochemical Sciences 7(02) (2006) 29-32.

[15] Heumann K. G., Baier K., Chromatographia 15(11) (1982) 701-703.

[16] Singare P. U., Lokhande R. S., Patil V. V., Prabhavalkar T. S., Tiwari S. R. D., European J. Chemistry 1(1) (2010) 47-49.

[17] Adachi S., Mizuno T., Matsuno R., J. Chromatogr. A 708 (1995) 177-183.

[18] Shuji A., Takcshi M., Ryuichi M., Biosci. Biotechnol. Biochem. 60(2) (1996) 338-340.

[19] Pravin U. Singare, International Letters of Chemistry, Physics and Astronomy 6 (2013) $1-5$.

[20] P. U. Singare, International Letters of Chemistry, Physics and Astronomy 12 (2013) 1-13.

[21] P. U. Singare, International Letters of Chemistry, Physics and Astronomy 12 (2013) 14-27. 